\title{
A combination of gangliosides and nerve growth factor alleviates lipopolysaccharide-induced neuronal cells damage and its mechanism
}

\author{
Ying Song ${ }^{1, a}$, Yun Bei ${ }^{1}$, Dongsheng Mao ${ }^{2}$, Wei Ding ${ }^{1}$ and Zhiyun Lin ${ }^{1}$ \\ ${ }^{1}$ College of Pharmaceutical Science, Zhejiang University of Technology, 310014 Hangzhou, China \\ ${ }^{2}$ Community Health Services Center of Mishixiang, Gongshu District, 310005 Hangzhou, China
}

\begin{abstract}
Objective: To evaluate the effect of gangliosides (GM1) in combination with nerve growth factor (NGF) against neuronal cells damage evoked by lipopolysaccharide (LPS), and tries to uncover its probable mechanism. Methods: (1) Cell viability was measured using Methyl thiazolyl tetrazolium (MTT) method, which was also determined the optimum concentration of LPS for the damage models; meanwhile, cell morphology was observed by microscope. (2) The expression level of NF- $\mathrm{kB}$ was detected by RT-PCR. (3) Finally, NF-kB inhibitor pyrollidine dithiocarbamate (PDTC) was treated for the research of NF- $\mathrm{kB}$ pathway. Results: (1) MTT results shown that the LPS injury was dose-dependent, and $100 \mathrm{nmol} / \mathrm{L}$ was selected as the optimum damage concentration. (2) Through the morphological observation, MTT and RT-PCR analysis, we found that GM1 and NGF both can protect cells against LPS injury; interestingly, combination of GM1 and NGF had a slighter LPS injury than GM1 administration alone. Moreover, the expression of NF- $\mathrm{kB}$ in combination group was lower than that in GM1 group, indicated that blockage of NF- $\mathrm{KB}$ pathway was better for cells living. Conclusion: Combination of GM1 and NGF has a better protective act on LPS injury than GM1 alone. The mechanism may have some connections with NF-kB pathways.
\end{abstract}

\section{Introduction}

Ganglioside (monosialoteterahexosyl gangliosides, GM1) is an important nerve protective agent in the brain [1]. In previous studies, several in vivo and in vitro models have been demonstrated that GM1 play an important role in cell-cell recognition and signal transduction pathways. GM1 has varieties of functions, such as stability maintaining the $\mathrm{Na}^{+}-\mathrm{K}^{+}$-ATP enzyme activity and cellular membrane, promoting the maturation of neuronal cells, regulating the proliferation of neural cells by polypeptide growth factor, protecting nerve cells from damage and promoting repairing after injury. Furthermore, GM1 can inhibit the toxicity of excitatory amino acid with enhanced role of neurotropic factor by blocking the translocation of protein kinase of PKC- $\alpha$ [2-4]. Studies have also proved that GM1 can relief the apoptosis of nerve cells after injury by the regulation of PKC signal pathway, but its protective effect on the LPS induced cell inflammatory injury need to be further researched [5]. In

\footnotetext{
${ }^{\text {a }}$ Corresponding author: songying@zjut.edu.cn
}

This work was supported by Grants-in-aid from the natural science foundation of Zhejiang province (No. LY17H090018) and the fund of national clinic pharmacology study (No. L2011079). 
recent years, with the increasing numbers of bacterial infections, especially the infection of Gramnegative bacterium, more and more researchers have focused on this issue. Some researches illustrated that GM1 have connections with other molecules, receptors or signal pathways, such as phospholipase $\mathrm{C} \gamma$ (PLC $\gamma$ )[6], tropomyosin receptor kinase (Trk) [7] and so on. However, little is known about the relationship between GM1 with NF- $\kappa \mathrm{B}$, particularly the joint action of GM1 and NGF with NF- $\kappa B$.

Nuclear factor $(\mathrm{NF}-\kappa \mathrm{B})$, as a multifarious transcription regulatory proteins, participate in regulating the expression of various inflammatory cytokines and cell apoptosis $[5,8]$, is attracting rising concerns and the research of its signal system is gradually becoming the hotspot in the field of neural biological science. Besides, some studies suggested that the activation of NF- $\kappa \mathrm{B}$ signaling pathway is sometimes dualistic, and the mechanism of how to induce apoptosis is not fully understand [9].

Both primary neurons and rat pheochromocytoma cell line (PC12 cells) were studied in this research, the protective effect of GM1 and NGF on LPS damage was observed by the alterative content of NF- $\kappa B$. In the current study, we found that LPS-induced cell damage had some contact with the activation of NF- $\mathrm{KB}$ in both PC12 cells and primary neurons; we also observed the effect of combined treatment of NGF and GM1, and tried to understand the mechanism of the action.

\section{Materials and methods}

\subsection{Materials}

\subsubsection{Chemicals}

GM1, NGF, LPS, PI (propidium iodide), PDTC (Pyrrole aldehyde disulfide carbamic acid) and Hoechst33342 were purchased from Sigma-Aldrich (Steinheim, Germany). 3-(4,5-dimethyl-2thiazolyl)-2,5-diphenyl-2-H-tetrazolium bromide (MTT) was purchased from Shanghai Biological Technology (Shanghai, China). DMEM and horse serum were purchased from Thermo Fisher Scientific (MA, USA). Fetal bovine serum was purchased from Sijiqing (Hangzhou, China).

\subsubsection{Primary neurons and PC12 cells}

Primary neurons were made according the reference from the Academy of Military Medical Sciences. Neonatal Sprague-Dawley (SD) rats were brought from the Laboratory Animal Centre of Zhejiang Academy of Medical Sciences. All the procedures were carried out under aseptic conditions [10]. In brief, the neonatal rat was sterilized by $70 \%$ ethyl alcohol and then conducted sacrifice; the brain was collected on ice plate to prepare tissue. The brain was put into ice-bathed dissecting fluid; cortex was separated by ophthalmic forceps, removed meningeal and vessels and put into the plate which is covered with dissecting fluid. The cortex was cut into the size of $1 \mathrm{~mm}^{2}$ and then washed by dissecting fluid twice. Put the tissue into pancreatic enzyme solution, digested in the temperature of $37^{\circ} \mathrm{C}$. 20 minutes later, discarded pancreatic enzyme, douched sediment with $3 \mathrm{ml}$ culture solution for two times. Added $2 \mathrm{ml}$ culture solution, beat upon for 10 15 times, made the cell suspension, standing the cell suspension for 1 2 min, Absorbed supernatant into another tube, added $2 \mathrm{ml}$ cultivation liquid, repeated percussion, and then combined the supernatant. The supernatant was filtered through 200mesh sieve. Take $25 \mu 1$ filtered liquid, added $475 \mu 1$ cultivation liquid, diluted for 20 times, then used for counting. Cells concentrate was diluted to $1 \times 10^{6} / \mathrm{ml}$ by cultivation liquid and inoculate into the plate (96-well plates, $100 \mu 1$ per well). On the first day after inoculation, Cell cultivation liquid was medium changed for every 3 days or 2 times a week. After cultivated for five days, nerve cells were deal with $3 \sim 5 \mu \mathrm{g} / \mathrm{ml}$ cytarabine (ARA-C), which is used for inhibited the excessively growth of glial cell. $48 \mathrm{~h}$ later, medium changed, and cultivated for another 10 days then can be used for the study.

PC 12 cells were obtained from Shanghai Institute of Cell (Shanghai, China). 


\subsection{The effect of GM1 on cells}

Both primary neurons and PC12 cells were seeded into 96 well plates and incubated with $100 \mu \mathrm{mol} / \mathrm{L}$, $10 \mu \mathrm{mol} / \mathrm{L}, 1 \mu \mathrm{mol} / \mathrm{L}, 0.1 \mu \mathrm{mol} / \mathrm{L}, 0.01 \mu \mathrm{mol} / \mathrm{L}$ or $0 \mu \mathrm{mol} / \mathrm{L}$ GM1 for $24 \mathrm{~h}$. Cell viability was assessed using MTT assay. Opacity density (OD) was measured at $570 \mathrm{~nm}$ using a spectrophotometer.

cell viability $(\%)=(O D$ of cells with different treatment $) /(O D$ of cells with no treatment $) \times 100$

\subsection{Establishment of LPS damage model}

Primary neurons and PC12 cells were plated into 96 well plates, treated with different concentration of LPS $(0 \mathrm{nmol} / \mathrm{L} 0.1 \mathrm{nmol} / \mathrm{L}, 1 \mathrm{nmol} / \mathrm{L}, 10 \mathrm{nmol} / \mathrm{L}, 100 \mathrm{nmol} / \mathrm{L}$ or $1000 \mathrm{nmol} / \mathrm{L})$ for $24 \mathrm{~h}$. Cell viability was determined by MTT assay as $\mathbf{2 . 2}$, and the optimum concentration of damage model were figured out by the MTT assay results.

\subsection{The protective effect of GM1, GM1 combined with NGF on LPS damaged cells}

Primary neurons and PC12 cells were separately divided into four groups: a control group (no specific treatment), a damage group (treated with $100 \mathrm{nmol} / \mathrm{L}$ of LPS, damage model group), a GM1 treatment group (treated with GM1 in damage model) and a combination treatment group [treated with GM1 and NGF $(50 \mathrm{ng} / \mathrm{ml})$ in damage model group]. The OD of each group was determined by MTT assay after treated for $24 \mathrm{~h}$.

\subsection{Morphological observation}

Inverted light optical microscopy (Nikon TS100, Tokyo, Japan) was performed to assess cell morphologies. Characteristic morphological features of in vitro PC12 cells and primary neurons were observed such as their characteristic shape and dendrite formation.

\subsection{The relative expression of NF-KB was detected by RT-PCR}

PC12 cells were seeded into 6 well plates, and four groups were separated as 2.4. The RNA of each group were extracted respectively and cultured for $24 \mathrm{~h}, \mathrm{NF}-\varkappa \mathrm{B}$ of each group was detected by RTPCR (F: CTTCTGGGCCATATGTGGAGAT; R: TCGCACTTGTAACGGAAACG), Reference is GAPDH (F: GGTGGACCTCATGGCCTACAT; R: GCCTCTCTCTTGCTCTCAGTATCCT). Primers sequences were designed by Beacon designer Express Primer 2.0, synthesized by Shanghai Biological Engineering Co., Ltd.

\subsection{LPS damage is related to NF-KB pathway or not}

Pyrollidine dithiocarbamate (PDTC) is a kind of inhibitor of NF- $x \mathrm{~B}$. In order to determine the LPS damage on cells is related to NF- $\varkappa \mathrm{B}$ pathway or not, cells were divided into three groups: a control group, a LPS damage group and a PDTC+LPS group. MTT assay was used to measure the role of NF$x \mathrm{~B}$ in $\mathrm{PC} 12$ cells or primary neurons.

\subsection{Statistical analysis}

Values were expressed as mean \pm SD. Statistical analysis was performed with One-way ANOVA using Graph Pad Prism software. P values less than 0.05 were considered statistically significant $(* P<$ $0.05 ; * * P<0.01)$. 


\section{Results}

\subsection{MTT assay on PC12 cells}

Viability of PC12 cells were assessment by MTT assay. The viability of control group was seen as $100 \%$. Although the viability of PC12 cells which treated with $0.001 \sim 10 \mu \mathrm{mol} / \mathrm{L}$ of GM1 were higher than control group, there was no significant difference (Figure1-a). That is to say GM1 alone cannot influence the living of PC12 cells. In Figure 1-b, cells incubated with a concentration gradient $(0.1 \sim 1000 \mu \mathrm{mol} / \mathrm{L})$ of LPS have revealed dramatically reduced survival rate. The mortality rate of cells were almost $50 \%$ while the dosage of LPS were between $10 \sim 1000 \mu \mathrm{mol} / \mathrm{L}$. According to the previous studies and our results, $100 \mu \mathrm{mol} / \mathrm{L}$ was chosen for put forward the damage model. The survival rate of LPS damaged PC12 cells was obviously increased with the administration of GM1, suggesting that GM1 can mitigate the injury of LPS (Figure 1-c), and $1 \mu \mathrm{mol} / \mathrm{L}$ of GM1 can relieve the LPS injury into minimum. In order to make the results more clear, we have concluded the above results together. Five groups have been divided: a LPS group $(100 \mu \mathrm{mol} / \mathrm{L}$ LPS, damage group), a GM1 group $(1 \mu \mathrm{mol} / \mathrm{L} \mathrm{GM} 1+100 \mu \mathrm{mol} / \mathrm{L} \mathrm{LPS})$ and a NGF group $(100 \mu \mathrm{mol} / \mathrm{L} \mathrm{LPS}+50 \mathrm{ng} / \mathrm{ml} \mathrm{NGF})$, a GM1+NGF group $(1 \mu \mathrm{mol} / \mathrm{L} \mathrm{GM} 1+100 \mu \mathrm{mol} / \mathrm{L} \mathrm{LPS}+50 \mathrm{ng} / \mathrm{ml} \mathrm{NGF})$ and a control group. Compared among these groups, we found that cells cultured with combination of NGF and GM1 have higher cell vitality, as is shown in figure1-d.
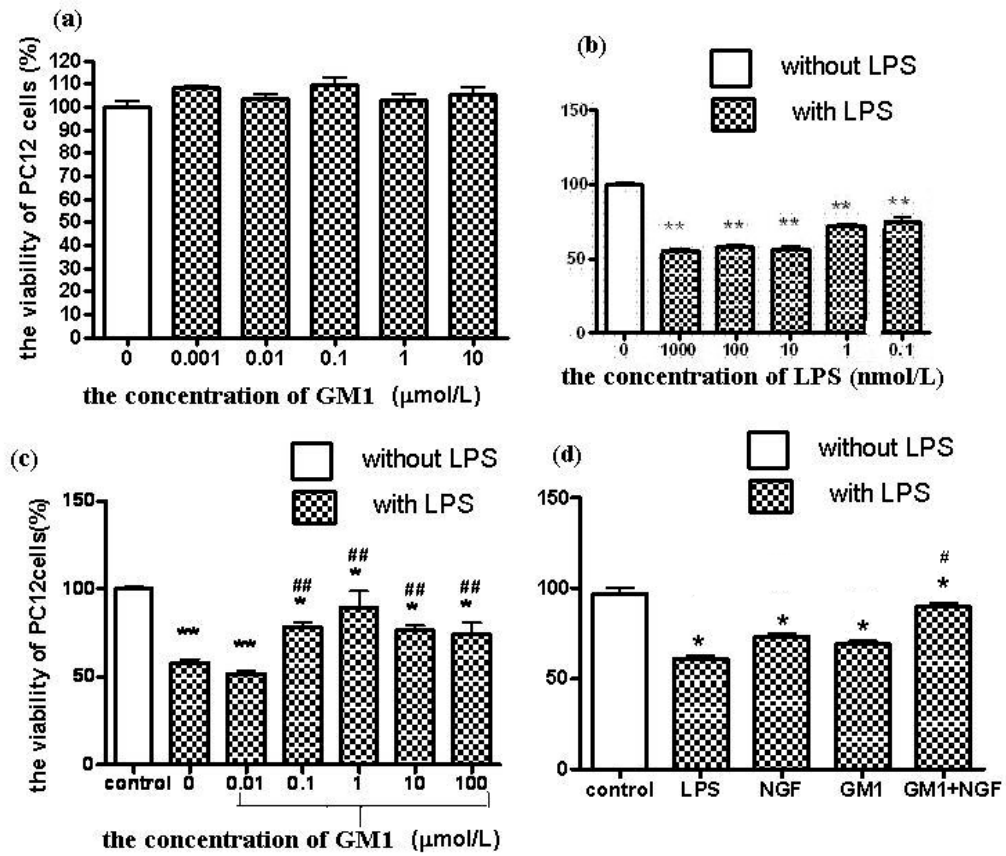

Figure 1. Effects of GM1/NGF on viability of PC12 cells. (a) The effect of GM1 on PC12 cells. GM1 (0$10 \mu \mathrm{mol} / \mathrm{L}$ ) alone have no significant influence on the viability of PC12 cells. (b) The effect of LPS on PC12 cells. With the incremental concentration of LPS, the sever injury has been caused on PC12 cells and 100nmol/L has been chose for the damage model. (c) The protective effect of GM1 on LPS injured PC12 cells. When the concentration of GM1 is higher than $0.1 \mu \mathrm{mol} / \mathrm{L}$; there shows a better protective effect. (d) The effect of GM1 and NGF on PC12 cells. The combination administration of GM1 and NGF can be sharply reduced the LPS damage than NGF or GM1 alone. Values were expressed as mean $\pm \mathrm{SD}(\mathrm{n}=6) .{ }^{*} P<0.05$ and ${ }^{* *} P<0.01$, compared to control group; $\# p<0.05$ and $\# \# p<0.05$ compared to GM1 group; Student's t-test. 


\subsection{MTT assay on primary neurons}

In primary neurons, survival rate was also assessed through MTT assay and all the method or procedure were the same as the study of PC12 cells. Similar results were obtained from the primary neurons: a. GM1 alone cannot influence the living of primary neurons (Figure 2-a); b. A concentration gradient $(0.1 \sim 1000 \mu \mathrm{mol} / \mathrm{L})$ of LPS can obviously reduce the cell survival rate in primary neurons, the optimum concentration for the damage model in primary neurons was also $100 \mu \mathrm{mol} / \mathrm{L}$ (Figure 2-b); c. $0.1 \sim 100 \mu \mathrm{mol} / \mathrm{L}$ of GM1 can notably protect the cells against LPS damage (Figure 2-c) and d. combination treatment of GM1 and NGF can remarkably enhanced the viability in LPS damaged primary neurons (Figure 2-d).
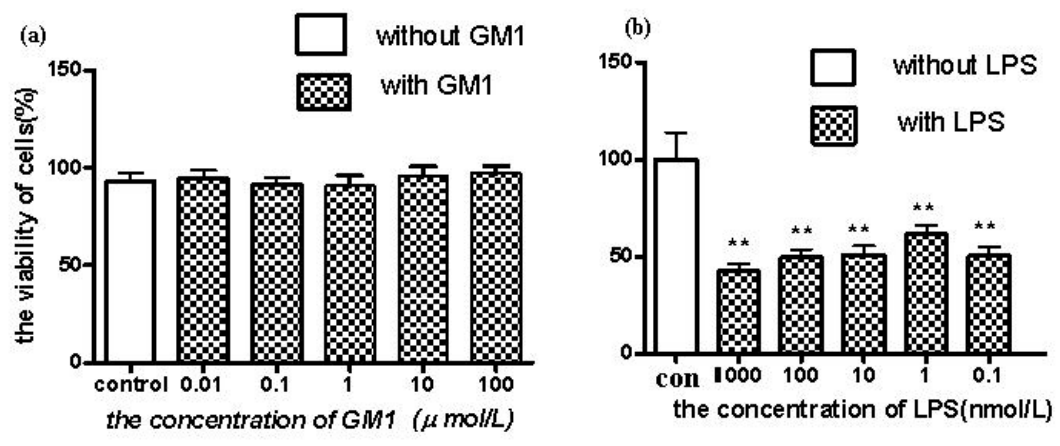

(c)

(d)
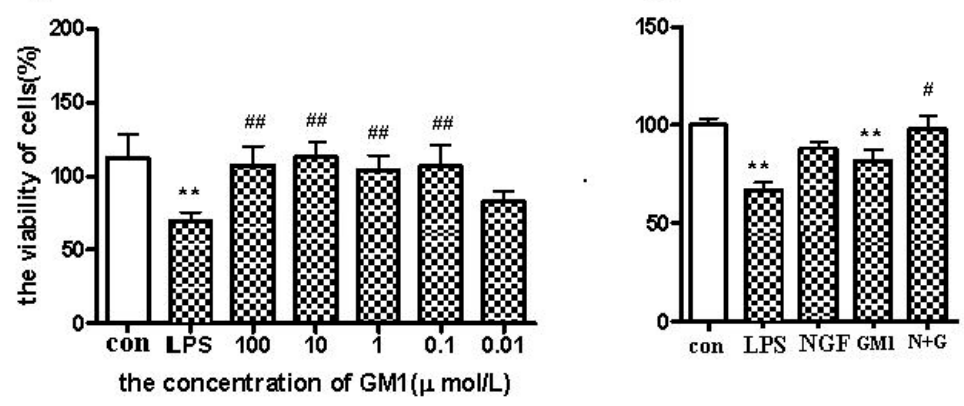

Figure 2. Effects of GM1/NGF on primary neurons viability. (a) The effect of GM1 on primary neurons. GM1 $(0-10 \mu \mathrm{mol} / \mathrm{L})$ alone also have no significant influence on the viability of primary neurons. (b) The effect of LPS on primary neurons. With the incremental concentration of LPS, the sever injury has been caused and we also chose $100 \mu \mathrm{mol} / \mathrm{L}$ for the establishment of damage model. (c) The protective effect of GM1 on LPS induced injury in primary neurons. When the concentration of GM1 was higher than $0.1 \mu \mathrm{mol} / \mathrm{L}$; there was an obviously increasing in the survival rate. (d) The cooperatively effect of GM1 and NGF on primary neurons. The results on both PC12 cells and primary neurons have been corporately shown that combination administration of GM1 and NGF has a stronger effective on the protection of LPS damage. Values were expressed as mean $\pm \mathrm{SD}(\mathrm{n}=6)$. $* P$ $<0.05$ and $* * P<0.01$, compared to control group; $\# p<0.05$ and $\# \# p<0.05$ compared to GM1 group; Student's ttest.

\subsection{Morphological observation of PC12 cells and primary neurons}

The morphological of control group, LPS damage group, GM1 treated LPS damage group and combination medication of GM1 and NGF in PC12 cells and primary neurons have been observed by an inverted microscope. The results were showed as the two pictures below: Figure 3 and Figure 4 . 

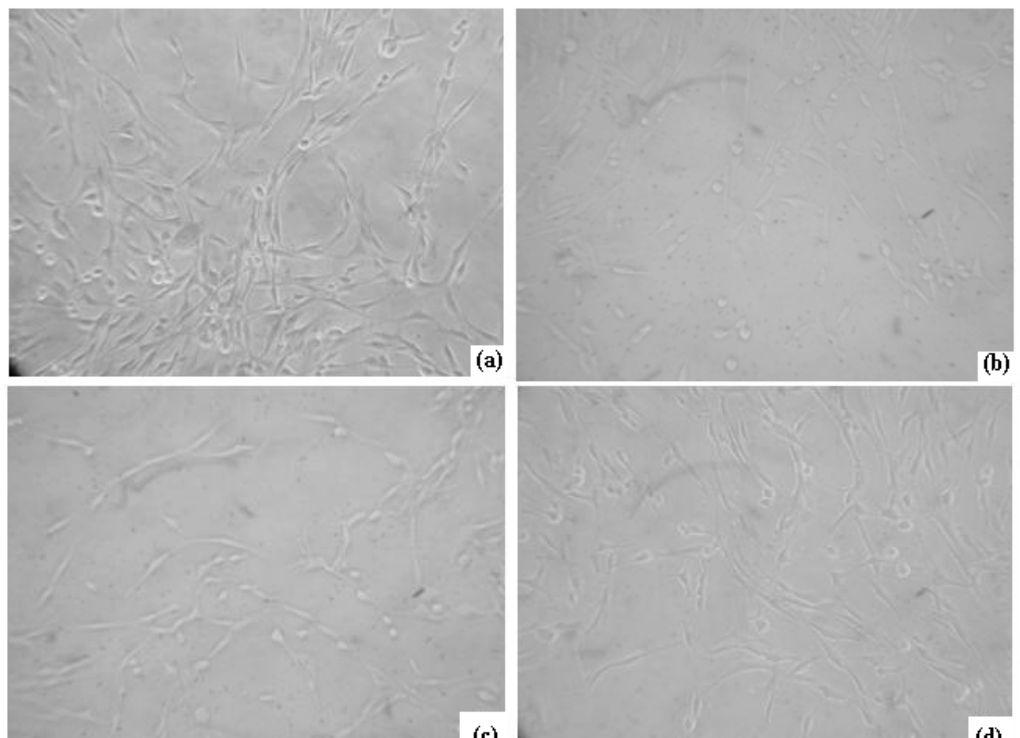

Figure 3. The morphology of PC12 cells. Normal differentiation of PC12 cells were clear in outline, and their shapes were round, spindle and ellipse, cells were also showed distributed like cluster, and dendrites were clearly to be seen (Figure 3-a). While the cells were damaged by LPS for 24 hours, the disappearances of cells were shrinking, flat and protuberances were disappeared (Figure 3-b); the damages of cells were reduced if we added GM1 into the LPS (Figure 3-c); in Figure 3-d, the protective effect of GM1 and NGF were much more significantly than GM1 alone, and the cell morphology in this group were similar to the control group.
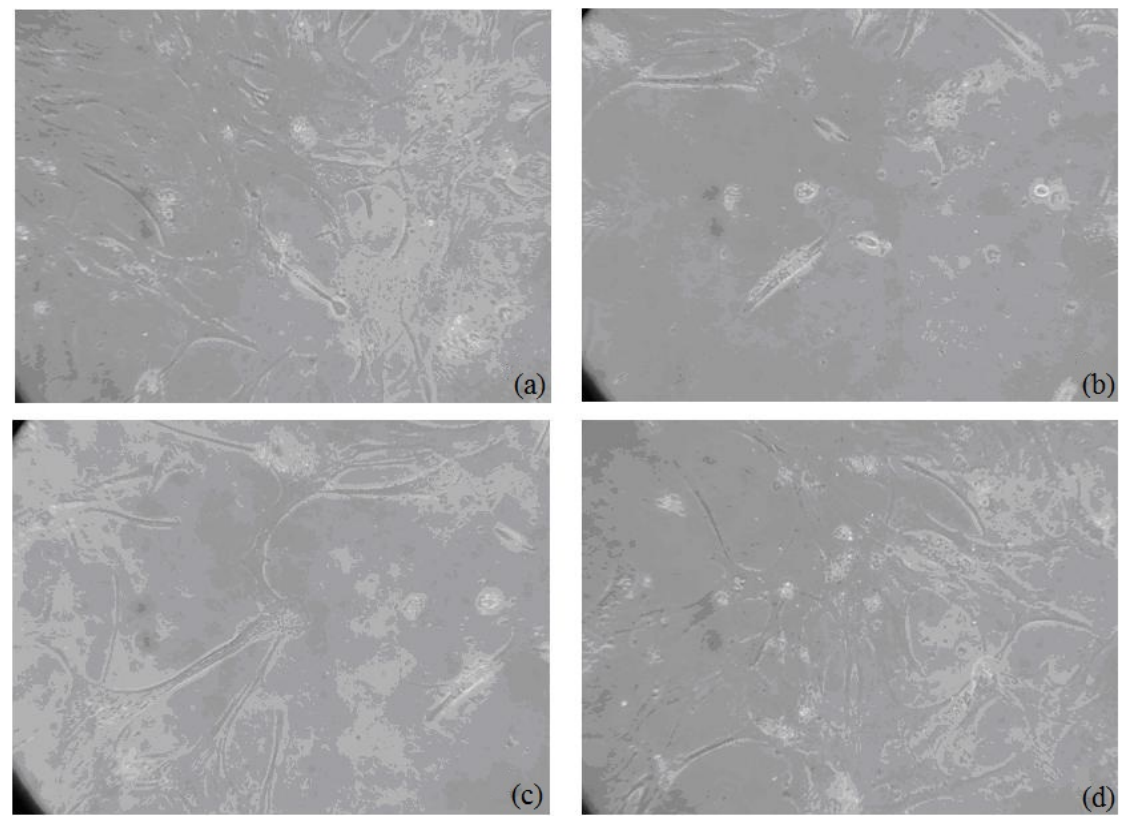

Figure 4. The morphology of primary neurons. Figure 4-a have described the normal living status of primary neurons. LPS damaged primary neurons were represented in Figure 4-b. The cells were less to see in the picture. As is shown in Figure4-c, GM1 have a certain protective effect on LPS induced damage; however, the combinations of GM1 and NGF have a stronger effect on LPS induced damage (Figure 4-d). 


\subsection{The relative expression of NF-KB was detected with RT-PCR}

The RT-PCR results showed that the relative expression of NF- $x \mathrm{~B}$ in LPS injured cells was significantly higher than that in control group. It is indicated that LPS damage can increased the expression of NF- $x \mathrm{~B}$ in $\mathrm{PC} 12$ cells. The relative expression of $\mathrm{NF}-x \mathrm{~B}$ in the drug treatment group was significantly lower than that of the injured cells, drug treatment decreased the expression of NF- $x \mathrm{~B}$, treatment with NGF and GM1 can recovered the injury to some extent, it is illustrated that NGF had a protective effect of damage by LPS, and the protective effect may related to the inhibiting activation of NF- $x \mathrm{~B}$ signaling pathway. The relative expression levels of NF- $x \mathrm{~B}$ in $\mathrm{PC} 12$ cells were detected by RT-PCR. The results were shown as Figure 5.
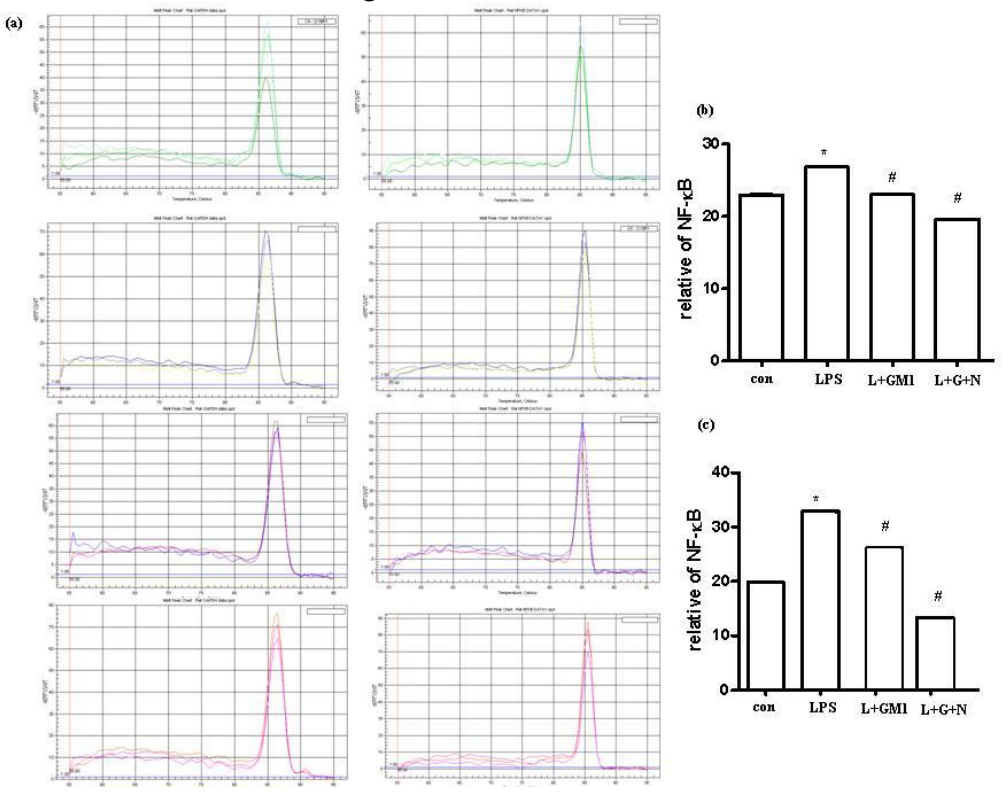

(c)

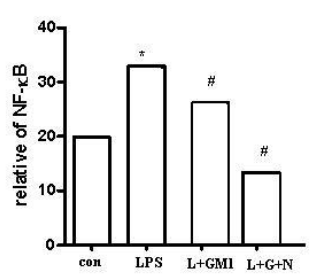

Figure 5. Relative expression levels of NF- $\mathrm{kB}$ in each group. (a) RT-PCR melting curve in different groups. The melting curve analysis revealed a mean melting temperature $(\mathrm{Tm})$ of $86.5 \pm 0.6^{\circ} \mathrm{C}$, and the samples showed only a small variation in the parameters. (b) Relatively expression of NF- $\mathrm{KB}$ in PC12 cells. NF- $\mathrm{kB}$ has been highly expressed in LPS group. The expression of NF- $\mathrm{kB}$ in GM1 and LPS group were the same as the normal group. The expression of NF- $\mathrm{kB}$ has been highly decreased in the combination of GM1 and NGF in LPS damaged PC12 cells. (c) Relatively expression of NF- $\mathrm{KB}$ in primary neurons. Compared with (b) and (c), it is demonstrated that the protective effect of GM1 and NGF were both effective in PC12 cells and primary neurons. Values were expressed as mean $\pm \mathrm{SD}(\mathrm{n}=4) ;{ }^{*} p<0.05$ and ${ }^{* *} p<0.01$, compared to control group, $\# p<0.05$ and $\# \# p<0.01$, compared to GM1 group; Student's t-test.

\subsection{The relationship between LPS damage and NF-kB pathway}

The results of RT-PCR have showed that the LPS damage and the protective of GM1 and NGF may relate to the expression of NF- $x \mathrm{~B}$. So we tried to figure out the deeper connection between $\mathrm{NF}-x \mathrm{~B}$ and the viability of LPS damaged PC12 cells and primary neurons by the using of NF- $x$ B inhibiter PDTC. The results were shown as Figure 6. The treatment of PDTC can significantly improve the viability of LPS injured PC12 cells and primary neurons. 
(a)

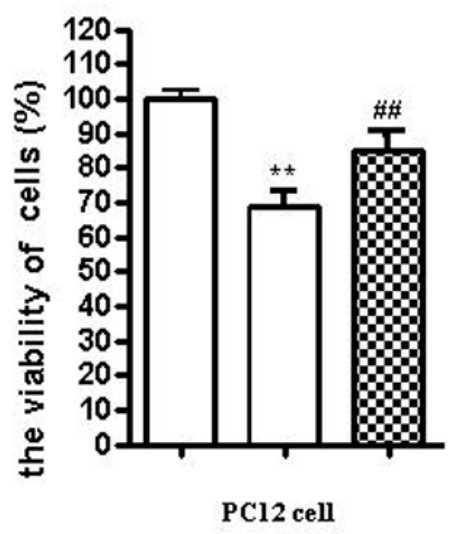

(b)

\section{$\square$ without PDTC}

with PDTC

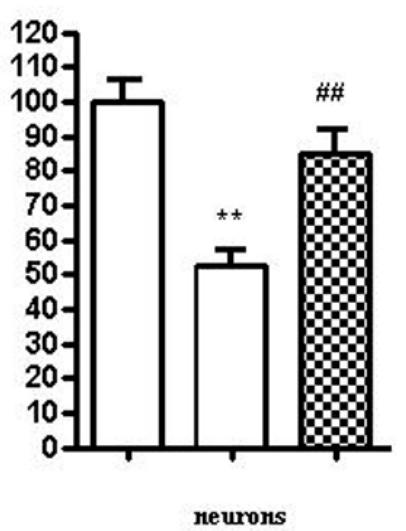

Figure 6. The effect of NF- $\mathrm{KB}$ inhibitor PDTC on LPS damaged PC12 cells and primary neurons. (a) The damaged cells which added PDTC had a higher viability than no-treatment damaged cells. That is to say the damage of LPS may have up-regulated the expression of NF- $\mathrm{kB}$. (b) In the study of primary neurons, result also showed that there may have a connection between LPS damage and NF- $\kappa B$ expression. Values were expressed as mean $\pm \mathrm{SD}(\mathrm{n}=6) ;{ }^{*} p<0.05$ and ${ }^{* *} p<0.01$, compared to control group, $\# p<0.05$ and $\# \# p<0.01$, compared to GM1 group; Student's t-test.

\section{Discussions}

In this experiment, we had known that PC12 cells can be damaged by LPS; and this injury was dosedependent, that is to say, the injury will be increased with the increasing concentration of LPS in a certain case. When the LPS concentration is as high as $100 \mathrm{nmol} / \mathrm{L}$, the cell survival rate was only $55 \%$; according to the previous study, we select $100 \mathrm{nmol} / \mathrm{L}$ as the concentration to build the injury model. The morphological observation results proved that LPS induced PC12 cell damage is not only manifested in the cell death, but also effect cells structures and functions. At the early stage of cell death, even if there is no exist of necrosis in cells, the synapses of the cells are disappeared; shrinkage is appeared in round injured cells. When the concentration of LPS is as high as $1 \mathrm{~mol} / \mathrm{L}$, the number of death cells increased significantly.

GM1, a group of sphingolipids which included sialic acid, are nutrients for the survival, growth, differentiation and function of neurons. Animal and clinical experiments showed that GM1 has certain protective and repairing effects for the injury of both central nervous system (CNS) and peripheral nervous system, including cerebrovascular diseases, diabetes, alcoholic and uremic neuropathy. GM1 also have some certain functions on biochemical index, symptoms improvement, delay of diseases progression, and protecting the neurons for CNS degenerative disease which including Parkinson's disease, senile dementia and so on. Our experiments have shown that GM1 has no toxic effects on neuronal cells, and has a protective effect on LPS damage. Its effective concentration is $0.1,1,10$, $100 \mu \mathrm{mol} / \mathrm{L}$, and $1 \mu \mathrm{mol} / \mathrm{L}$ is the most effective concentration. Morphological observation also revealed that GM1 can obviously improve the survival cells induced by LPS, which is consistent with the previous studies. In our research, we have studied on both PC12 cells and primary neurons, which made our research much more precise and convictive.

$\mathrm{NF}-\boldsymbol{x B}$ is a central substance that mediates a number of immune and inflammatory responses. It is also an important transcriptional regulator of apoptosis signaling pathway, but its effect on neuronal cells is in the dispute [11-12]. Our experiments have used RT-PCR to detect the expression levels of $\mathrm{NF}-x \mathrm{~B}$, the results showed that the expression levels of NF- $x \mathrm{~B}$ in LPS injured PC12 cells and primary 
neurons were significantly higher than those in control group, which indicated that the expression of $\mathrm{NF}-x \mathrm{~B}$ is associated with LPS induced injury, and the more serious damage it takes, the higher expression level of NF- $x \mathrm{~B}$. This is accordance with the previous study which the AD patients with severe neuronal apoptosis in brain tissue have a higher activation level of NF- $x \mathrm{~B}$ [13]. In addition, the expression level of $\mathrm{NF}-\varkappa \mathrm{B}$ in the treatment group was lower than that in the injury group, which was similar to the normal cells, indicated that decreased injury can reduce the expression of $\mathrm{NF}-\varkappa \mathrm{B}$, and which is also an indicator for the protective effect of LPS damage. But there are some studies showed that apoptosis will be occurred when PC12 cell were in the condition of the decreased content of NF$x \mathrm{~B}$, this indicate that the content of NF- $x \mathrm{~B}$ in cells needs to be maintained at a certain amount, the increased or decreased amount will lead the cells to apoptosis [14]. And the experimental results shown that treated with GM1 combined with NGF have a better protective effect in cells. It is illustrated that in PC12 cells, the expression level of $\mathrm{NF}-x \mathrm{~B}$ in normal cells or combination administrated GM1 and NGF cells are approximately the same.

In Conclusion, LPS can induce the damages of PC12 cells, which will lead cells to death. The change of expression of NF- $x \mathrm{~B}$ was detected in damage models. We can speculate that there is a certain relationship between the expression of NF- $\varkappa$ B and LPS damage. Instead, GM1 has a protective effect on LPS injury, and the protections will much more obviously if we combined administration with NGF. It should be mentioned that previously studies had reveal that GM1 may play an important role in the activating the functions of NGF [15]. Our results showed that the phenomenon of death cells was decreased, so, GM1 may play a role to slow down or block the process of cell death. This phenomenon illustrated that the LPS damage and the protective effect of GM1 on LPS injury may relate to the activation of NF- $x \mathrm{~B}$ signaling pathway. Finally, MTT assay confirmed the conclusion that there is a relationship between LPS damage and NF- $x \mathrm{~B}$ signaling pathway by the using of NF- $x \mathrm{~B}$ inhibitor PDTC.

\section{References}

1. Sandhoff K., Harzer K., J. Neurosci. Gangliosides and gangliosidoses: principles of molecular and metabolic pathogenesis. 25, 10195-10208 (2013).

2. Giordano G., Sanchez-Perez A.M., Burgal M., et al. J. Neurochem. Chronic exposure to ammonia induces isoform reselective alterations in the intracellular distribution and NMDA receptormediated translocation of protein kinas $C$ in cerebellar neurons in culture. 1, 143-157 (2005).

3. Lallemend F., Hadjab S., Hans G., et al. J. cell. Sci. Activation of protein kinase CbetaI constitutes a new neurotrophic pathway for deafferented spiral ganglionneurons. 19, 4511-4525 (2005).

4. Yates A. J., Saqr H.E., Van Brocklyn J. J. Neurooncol. Ganglioside modulation of the PDGF receptor. A model for ganglioside functions. 1, 65-73 (1995).

5. Beni S.M., Tsenter J., Alexandrovich A.G., et a1. J. Cereb Blood Flow Metab. CuZn SOD deficiency, rather than overexpression, is associated with enhanced recovery and attenuated activation of NF-kappa B after brain trauma in mice. 4, 478-490 (2006).

6. Duchemin A. M., Ren Q., Neff N.H., Hadjiconstantinou M. J. Neurosci. GM1-induced activation of phosphatidylinositol 3-kinase: involvement of Trk receptors. 104, 1466-1477 (2008).

7. Duchemin A. M., Ren Q., Mo L., et al. J. Neurosci. GM1 ganglioside induces phosphorylation and activation of Trk and Erk in brain. 81, 696-707 (2002).

8. Israel A. Trends Cell Biol. The IKK complex: an integrator of all signals that activate NF-xB. 10, 129-133 (2000).

9. A. Campos, V. Vasconcelos. Int. J. Mol. Sci. Molecular mechanisms of microcystin toxicity in animal cells. 11, 268-287 (2010).

10. Wiemerslage L., Ismael S., Lee D. Mitochondrion. Early alterations of mitochondrial morphology in dopaminergic neurons from Parkinson's disease-like pathology and time-dependent neuroprotection with D2 receptor activation. (2016).

11. Zhen Y., Wang B., Zhou W.Q. Chinese Journal of Clinical Rehabilitation. The apoptosis effect of salicylic acid on P12 cells. 6, 70-72 (2006). 
12. Ayumi T., Katsumi H., et al. J. Neurochem. Lysosomal accumulation of Trk protein in brain of GM1-gangliosidosis mouse and its restoration by chemical chaperone. 3, 399-406 (2011).

13. Ji H., Zhang X., Du Y., Liu H., Li S., et al. Brain. Res. Bull. Polydatin modulates inflammation by decreasing NF-xB activation and oxidative stress by increasing Gli1, Ptch1, SOD1 expression and ameliorates blood-brain barrier permeability for its neuroprotective effect in pMCAO rat brain. $\mathbf{1}$, 50-59 (2012).

14. Mattson M.P. J. Neurochem. NF-kappa B in the survival and plasticity of neurons. 6, 883-893 (2005).

15. Dragicevic N., Delic V., Cao C., et al. Neuropharmacology. Caffeine increases mitochondrial function and blocks melatonin signaling to mitochondria in Alzheimer's mice and cells. 8, 13681379 (2012). 